\title{
Infiltração de água no solo em sistemas de plantio direto e convencional
}

\author{
Teodorico Alves Sobrinho ${ }^{1}$, Antônio C. T. Vitorino ${ }^{1}$, Luiz C. F. de Souza ${ }^{1}$,
} Manoel C. Gonçalves ${ }^{1} \&$ Daniel F. de Carvalho ${ }^{2}$

\begin{abstract}
1 UFMS. CP 533, CEP 79804-970, Dourados, MS. Fone: (67) 411-3826. E-mail: talves@ceud.ufms.br (Foto) 2 UFRRJ/IT/DE. CEP 23890-000, Seropédica, RJ. Fone: (21) 2682-1865. E-mail: carvalho@ufrrj.br
\end{abstract}

Protocolo 156 - 25/10/2002 - Aprovado em 5/6/2003

\begin{abstract}
Resumo: Objetivou-se, através deste trabalho, estudar a infiltração de água em solo cultivado sob diferentes sistemas de manejo e rotação de culturas e a análise da adequação das equações de Horton e Kostiakov-Lewis para a estimativa da taxa de infiltração da água no solo, utilizandose infiltrômetro de aspersão. As estimativas da infiltração foram realizadas em quatro sistemas de sucessão de culturas cultivadas em parcelas de plantio direto e convencional. A qualidade do ajuste dos modelos foi avaliada por meio de regressões não-lineares entre os valores estimados e os valores médios observados em cada tratamento estudado. Concluiu-se que o sistema plantio direto proporcionou valores de taxa de infiltração estável de água no solo superiores aos do preparo convencional e, entre os tratamentos estudados, a sucessão soja-aveia ofereceu o maior valor de taxa de infiltração final. A qualidade do ajuste dos modelos foi satisfatória e a equação de Horton mostrou-se mais adequada para a estimativa da taxa de infiltração.
\end{abstract}

Palavras-chave: taxa de infiltração, infiltrômetro de aspersão, manejo de solo

\section{Water infiltration in the soil under no tillage and conventional tillage systems}

\begin{abstract}
This work had the objective of studying the infiltration of water in cultivated soil under different tillage systems and crop rotation and the adaptation of Horton and KostiakovLewis equations for estimating the water infiltration rate using a portable sprinkler infiltrometer. Field tests were accomplished in four systems of crop rotation, cultivated in plots of no tillage and conventional tillage systems. The quality of adjustment of models was evaluated through non-linear regressions among estimated values and mean values observed for each treatment. It may be concluded that the no tillage system provided values of water infiltration rate in the soil higher than the conventional tillage system; among the studied treatments, the succession soybeanoat provided higher value of the final infiltration rate. The quality of the adjustment of models was satisfactory and the equation of Horton proved to be more adequate for estimating the rate of infiltration.
\end{abstract}

Key words: infiltration rate, sprinkler infiltrometer, soil tillage

\section{INTRODUÇÃO}

A infiltração é o processo pelo qual a água penetra no perfil do solo. Inicialmente, seu valor é elevado, diminuindo com o tempo, até se tornar constante no momento em que o solo fica saturado. Assim sendo, sob chuva ou irrigação contínuas, a taxa de infiltração se aproxima, gradualmente, de um valor mínimo e constante, conhecido por taxa de infiltração básica (TIB). Dados de TIB são imprescindíveis nos modelos utilizados para a descrição da infiltração de água no solo e dependem do selamento superficial provocado pelo impacto das gotas de chuva na superfície do solo.

O processo de infiltração é de importância prática por que, muitas vezes, determina o balanço de água na zona das raízes e o deflúvio superficial, responsável pela erosão hídrica. Assim, o conhecimento do processo e sua relação com as características do solo são de fundamental significância para o eficiente manejo do solo e da água nos cultivos agrícolas (Reichardt, 1996).

De acordo com Carduro \& Dorfman (1988) condições tais como: porosidade, umidade, atividade biológica, cobertura vegetal, rugosidade superficial e declividade do terreno, dentre outras, influem grandemente na infiltração da água no solo. Segundo Reichert et al. (1992) a textura do solo afeta o salpico de partículas provocado pelo impacto das gotas de chuva, contribuindo para uma redução da porosidade da camada superficial do solo. Além do impacto da gota, Morin \& van Winkel (1996) citam a dispersão físico-química das argilas do 
solo como causa da formação do selamento superficial e, conseqüientemente, da redução da taxa de infiltração.

Segundo Bertol et al. (2001) em solos intensamente cultivados o surgimento de camadas compactadas determina a diminuição do volume de poros ocupado pelo ar e o aumento na retenção de água. Em decorrência disto, foi observado pelos autores diminuição da taxa de infiltração de água no solo, com conseqüente aumento das taxas de escoamento superficial e de erosão.

Sales et al. (1999) avaliando a associação da TIB com atributos físicos das camadas superficial e subsuperficial de um Latossolo Roxo e um Podzólico Vermelho-Amarelo, concluíram que seus valores são bastante contrastantes, podendo-se associar esses resultados às distintas características morfológicas relativas à estrutura dos horizontes desses solos. Os autores encontraram valor de $12,1 \mathrm{~mm} \mathrm{~h}^{-1}$ para a TIB no Podzólico Vermelho-Amarelo, possuindo $422 \mathrm{~g}$ $\mathrm{kg}^{-1}$ de argila e volume de macroporos de 7,8\% enquanto para o Latossolo Roxo, com $653 \mathrm{~g} \mathrm{~kg}^{-1}$ e 16,8\% de macroporos, a TIB atingiu valor de 56,6 $\mathrm{mm} \mathrm{h}^{-1}$. Por outro lado, Silva \& Kato (1998), trabalhando em Latossolo Vermelho-Amarelo com cobertura vegetal, encontraram valores de TIB variando de 56 a $96 \mathrm{~mm} \mathrm{~h}^{-1}$ e, sem cobertura vegetal, o valor da TIB variou de 51 a $78 \mathrm{~mm} \mathrm{~h}^{-1}$, caracterizando o efeito positivo da cobertura vegetal na infiltração de água no solo. Alves \& Cabena (1999) trabalhando sob dois sistemas de cultivo, plantio direto e plantio convencional, sob chuva simulada, concluíram que a infiltração acumulada e a TIB foram maiores no sistema de plantio direto.

O processo de infiltração da água no solo pode ser descrito por diversas equações ou modelos, alguns desenvolvidos a partir de considerações físicas, enquanto outros o são de forma empírica. Um modelo físico que supõe o solo semelhante a um feixe de microtubos, é a conhecida equação de Green-Ampt, que fornece a taxa de infiltração instantânea em função de atributos físicos do solo e do total infiltrado. Mein \& Larson (1973) citados por Silva \& Kato (1998) integraram a equação proposta por Green-Ampt, nos limites de integração próprios, conforme a duração da chuva. A partir de então, o modelo de Green-Ampt passou a ser conhecido como modelo de GreenAmpt modificado por Mein \& Larson, que fornece o total infiltrado de acordo com a intensidade e duração das chuvas. A obtenção dos parâmetros desse modelo envolve determinações de campo e rotinas computacionais, dificultando sua utilização.

Um modelo empírico mas muito empregado em manejo de irrigação, é a equação de Kostiakov-Lewis, normalmente utilizada para a estimativa da infiltração acumulada, cujos parâmetros não têm significado físico próprio e são estimados a partir de dados experimentais. Outro modelo mais consistente que o de Kostiakov-Lewis, é a equação de Horton, escrita na forma de uma função exponencial. Segundo o modelo de Horton, descrito por Prevedello (1996) a redução na taxa de infiltração com o tempo é fortemente controlada por fatores que operam na superfície do solo, tais como selamento superficial, devido ao impacto das gotas de chuva, fenômenos de expansão e contração do solo. Esses modelos apresentam coeficientes que podem ser calculados a partir das equações teóricas, ou serem estimados por meio de regressão, a partir de dados de infiltração medidos no campo.
Assim, o presente trabalho teve por objetivo avaliar a infiltração e verificar a adequação das equações de Horton e Kostiakov-Lewis, na estimativa da taxa de infiltração da água em diferentes sistemas de cultivo e de manejo de solo.

\section{MATERIAL E MÉTODOS}

O estudo foi realizado no Campus da Universidade Federal de Mato Grosso do Sul, em Dourados, MS (latitude 22¹3'16”S, longitude $54^{\circ} 17^{\prime} 01^{\prime \prime} \mathrm{W}$ e altitude de $430 \mathrm{~m}$ ), em solo classificado como Latossolo Vermelho distroférrico (EMBRAPA, 1999), textura muito argilosa, nos meses de setembro e outubro de 2001. O clima regional classificado pelo sistema internacional de Koppen e é do tipo Cwa, clima úmido e inverno seco, com precipitação média anual de $1500 \mathrm{~mm}$ e temperatura média anual de $22{ }^{\circ} \mathrm{C}$. A área experimental possui declividade média de $2 \%$ e alguns atributos do solo estudado, após três anos de cultivo com sucessão de culturas, são apresentados na Tabela 1.

Tabela 1. Alguns atributos do solo estudado

\begin{tabular}{|c|c|c|c|c|}
\hline & \multicolumn{4}{|c|}{ Tensão $(\mathrm{kPa})$} \\
\hline & 10 & 50 & 100 & 1500 \\
\hline \multirow[t]{2}{*}{ Umidade $0-0,20 \mathrm{~m}$ (\% vol.) } & 46,30 & 42,79 & 41,71 & 38,06 \\
\hline & \multicolumn{4}{|c|}{ Valores por Tratamento $\left(\mathrm{g} \mathrm{kg}^{-1}\right)$} \\
\hline Classe textural & Trat1 & Trat2 & Trat3 & Trat4 \\
\hline Argila & 692,3 & 658,3 & 657,7 & 657,3 \\
\hline Silte & 51,9 & 93,2 & 93,0 & 86,6 \\
\hline Areia fina & 163,4 & 148,7 & 161,4 & 158,0 \\
\hline Areia grossa & 92,3 & 99,7 & 87,8 & 98,0 \\
\hline Matéria orgânica $\left(\mathrm{g} \mathrm{dm}^{-3}\right)$ & 28,5 & 24,8 & 27,1 & 28,5 \\
\hline Profundidade (m) & \multicolumn{4}{|c|}{ Macroporosidade (\%) } \\
\hline $0-0,10$ & 8,24 & 13,65 & 11,05 & 7,59 \\
\hline \multirow[t]{2}{*}{$0,10-0,20$} & 6,37 & 5,42 & 6,94 & 3,17 \\
\hline & \multicolumn{4}{|c|}{ Porosidade Total $(\%)$} \\
\hline $0-0,10$ & 28,46 & 30,85 & 28,51 & 28,55 \\
\hline \multirow[t]{2}{*}{$0,10-0,20$} & 26,55 & 26,53 & 27,16 & 24,35 \\
\hline & \multicolumn{4}{|c|}{ Densidade do Solo $\left(\mathrm{kg} \mathrm{m}^{-3}\right)$} \\
\hline $0-0,20$ & 1.680 & 1.660 & 1.670 & 1.690 \\
\hline $0,20-0,40$ & 1.640 & 1.620 & 1.630 & 1.650 \\
\hline $0,40-0,60$ & 1.580 & 1.560 & 1.570 & 1.590 \\
\hline
\end{tabular}

Os testes de campo com o simulador de chuvas portátil denominado infiltrômetro de aspersão InfiAsper (Alves Sobrinho et al., 2002), foram realizados após a colheita das culturas de inverno, ano agrícola 2000/2001, em quatro sistemas de sucessão de culturas cultivadas em parcelas de plantio direto e em plantio convencional, tendo cada parcela de cultivo $10 \mathrm{~m}$ de largura por $36 \mathrm{~m}$ de comprimento. Os sistemas de sucessão correspondentes aos tratamentos avaliados sob plantio direto, foram: soja, seguida de cultivo de nabo forrageiro (Trat1); soja, seguida de cultivo de aveia (Trat2); soja, seguida de pousio (Trat3) e, sob plantio convencional, foi soja seguida de pousio no inverno (Trat4). O plantio convencional correspondeu a uma operação com grade aradora seguido de duas operações com grade niveladora. 
Os tratamentos foram dispostos no delineamento experimental de blocos casualizados com quatro repetições, totalizando 12 testes com o infiltrômetro na área de plantio direto e quatro na área de plantio convencional, nos diferentes sistemas de sucessão. Para avaliar o efeito de tratamentos e obter uma estimativa da variância residual, foi feita análise de variância dos dados obtidos.

O infiltrômetro de aspersão foi calibrado para aplicar uma intensidade de precipitação de $55 \mathrm{~mm} \mathrm{~h}^{-1}$, utilizando-se bicos Veejet 80.150 e pressão de $32 \mathrm{kPa}$. Antes de cada determinação no campo com o infiltrômetro eram coletadas, com auxílio de um trado, amostras de solo para determinação de umidade. As amostras eram retiradas a $0,10 \mathrm{~m}$ das parcelas teste, nas profundidades de 0 a 0,$20 ; 0,20$ a 0,40 e de 0,40 a $0,60 \mathrm{~m}$, com três repetições. Com os dados de intensidade da chuva simulada pelo infiltrômetro e pressão de serviço, calculou-se a energia cinética das gotas, causada pela precipitação, utilizando-se do programa computacional EnerChuva (Alves Sobrinho et al., 2001).

A medição do escoamento superficial se deu em sucessivos intervalos de tempo de 1, 2, 5, 10 e 15 min, com 5 repetições para cada intervalo, até que o escoamento se tornasse constante, enquanto em cada intervalo de tempo considerado foi coletado e medido o volume de água escoado durante $1 \mathrm{~min}$, ou seja, ao iniciar o escoamento coletava-se, durante $1 \mathrm{~min}$, o volume escoado, aguardava-se o intervalo de $1 \mathrm{~min}$ e em seguida se coletava o volume novamente durante $1 \mathrm{~min}$. Este procedimento era repetido cinco vezes e, então, passava-se para o intervalo seguinte de $2 \mathrm{~min}$, coletando-se o volume escoado durante 1 min e se aguardava $2 \mathrm{~min}$, repetindo-se cinco vezes. O volume escoado era considerado estabilizado ou constante no tempo, quando pelo menos três sucessivos valores medidos desse volume fossem iguais.

A lâmina de escoamento superficial foi determinada pela relação entre o volume de água escoado e a área de $0,70 \mathrm{~m}^{2} \mathrm{da}$ parcela teste que recebia a precipitação. A lâmina de água infiltrada foi calculada pela diferença entre a lâmina de água aplicada e a lâmina de escoamento superficial, em cada intervalo de tempo. Os valores de taxa de infiltração foram obtidos pela relação entre lâmina infiltrada e tempo de infiltração considerado.

Com os dados de taxa de infiltração obtidos no campo, verificou-se a adequação dos modelos de Horton (Eq. 1) e Kostiakov-Lewis (Eq. 2) para a estimativa da taxa de infiltração da água, nos diferentes sistemas de cultivo e de manejo de solo.

$$
\begin{gathered}
i=i_{f}+\left(i_{o}-i_{f}\right) \exp (-\beta t) \\
i=a k t^{(\alpha-1)}+i_{f}
\end{gathered}
$$

em que:

$\mathrm{i}_{\mathrm{o}} \quad$ - taxa de infiltração inicial observada, $\mathrm{mm} \mathrm{h}^{-1}$

$i_{f} \quad$ - taxa de infiltração final, $\mathrm{mm} \mathrm{h}^{-1}$ $\alpha, \beta$ e k - parâmetros estatísticos

t $\quad$ - tempo de infiltração considerado, min

Os parâmetros $\alpha, \beta$ e k, foram estimados utilizando-se o método de Gauss-Newton, minimizando-se a soma dos quadrados dos desvios em relação aos valores de taxa de infiltração obtidos nos testes de campo.

A qualidade do ajuste dos modelos foi avaliada por meio de regressões não lineares entre os valores estimados e os valores médios observados em cada tratamento estudado, juntamente com os respectivos coeficientes de determinação. Na avaliação, foram também utilizados os seguintes índices estatísticos: coeficiente de massa residual (CMR), coeficiente de ajuste (CA) e eficiência (EF), representados, respectiva-mente, pelas Eqs. (3), (4) e (5).

$$
\begin{gathered}
\mathrm{CMR}=\left(\sum_{\mathrm{i}=1}^{\mathrm{n}} \mathrm{O}_{\mathrm{i}}-\sum_{\mathrm{i}=1}^{\mathrm{n}} \mathrm{P}_{\mathrm{i}}\right) / \sum_{\mathrm{i}=1}^{\mathrm{n}} \mathrm{O}_{\mathrm{i}} \\
\mathrm{CA}=\sum_{\mathrm{i}=1}^{\mathrm{n}}\left(\mathrm{O}_{\mathrm{i}}-\overline{\mathrm{O}}\right)^{2} / \sum_{\mathrm{i}=1}^{\mathrm{n}}\left(\mathrm{P}_{\mathrm{i}}-\overline{\mathrm{O}}\right)^{2} \\
\mathrm{EF}=\left[\sum_{\mathrm{i}=1}^{\mathrm{n}}\left(\mathrm{O}_{\mathrm{i}}-\overline{\mathrm{O}}\right)^{2} / \sum_{\mathrm{i}=1}^{\mathrm{n}}\left(\mathrm{O}_{\mathrm{i}}-\overline{\mathrm{P}}\right)^{2}\right] / \sum_{\mathrm{i}=1}^{\mathrm{n}}\left(\mathrm{O}_{\mathrm{i}}-\overline{\mathrm{O}}\right)^{2}
\end{gathered}
$$

em que: $\mathrm{O}_{\mathrm{i}}$ representa os valores observados, $\mathrm{P}_{\mathrm{i}}$ os estimados, n é o número de observações, $\overline{\mathrm{O}}$ a média aritmética das observações e $\overline{\mathrm{P}}$ a média aritmética dos valores estimados.

\section{RESULTADOS E DISCUSSÃO}

Os valores médios observados para umidade do solo, intensidade de aplicação de água, energia cinética da chuva simulada na parcela e taxa de infiltração, estão apresentados na Tabela 2.

Tabela 2. Valores médios de umidade, intensidade de aplicação, energia cinética simulada e taxa de infiltração inicial e final

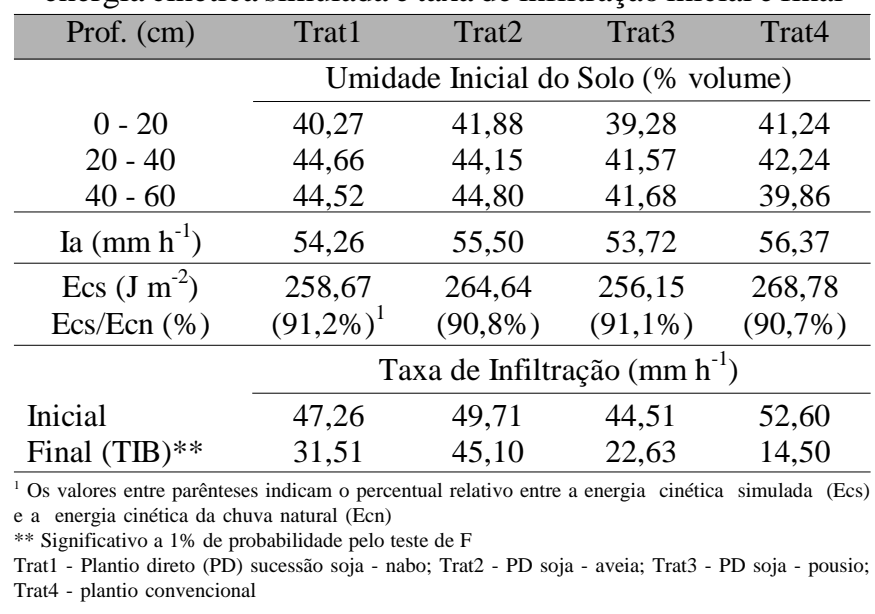




\section{Avaliação da taxa de infiltração da água}

$\mathrm{O}$ solo da área experimental, apesar de ser muito argiloso, apresenta faixa de umidade disponível de $7 \%$ entre as tensões de 10 e $1500 \mathrm{kPa}$, correspondente à diferença entre a umidade do solo na capacidade de campo (46\%) e a do ponto de murcha permanente $(38 \%)$ respectivamente. Esta particularidade, estreita faixa de umidade disponível, é devida ao arranjo de suas partículas de argila em pequenos grânulos, com alta capacidade de retenção de água, mas que não fica disponível para as plantas. Assim, em não havendo impedimento físico, esta característica faz com que este solo apresente comportamento relativo à infiltração de água, semelhante ao de um solo classificado como arenoso. Esses resultados corroboram com os dados de Ferreira et al. (1999) e de Resende et al. (2002) que afirmam parecer razoável admitirse que, quanto mais argiloso for o latossolo, maior será sua permeabilidade.

A calibração do infiltrômetro proporcionou valores de intensidade de aplicação não exatamente iguais, nos quatro tratamentos, devido às características operacionais e de montagem do equipamento no campo; no entanto, o percentual relativo de suas respectivas energias cinéticas foi semelhante aos valores médios próximos de $91 \%$ (Tabela 3 ), bem acima, portanto, do valor mínimo necessário proposto por Meyer \& McCune (1958) que é de 75\%. Considerando-se que a energia cinética da chuva é uma das propriedades que determinam a maior ou menor desagregação superficial do solo (Agassi \& Bradford, 1999) contribuindo para a formação do selamento superficial, pode-se assumir que as variações observadas na intensidade de precipitação não influenciaram na magnitude dos valores de energia cinética.

Dado o elevado nível de variabilidade espacial a que os solos estão submetidos, o coeficiente de variação de 17,5\%, obtido pela análise estatística dos valores de taxa de infiltração, caracteriza um bom nível de precisão experimental. Pela análise de variância dos dados experimentais, verificou-se diferença estatística para tratamentos, ao nível de $1 \%$ de probabilidade pelo teste de F. Os valores encontrados para taxa de infiltração final foram maiores nas parcelas de plantio direto, notadamente no tratamento 2 , tendo como sucessão as culturas de soja e aveia (Tabela 2). Os resultados evidenciam a interferência de alguns atributos ou fatores de solo na magnitude da TIB, especialmente a macroporosidade, o tipo de manejo e o selamento superficial. A cobertura mais homogênea do solo obtida com o cultivo de aveia no inverno, associada com o seu característico desenvolvimento radicular, proporcionou condições mais favoráveis à infiltração de água no solo, sobretudo pela quantidade de palha existente na superfície do solo, o que reduz o problema relativo ao selamento superficial. Os valores de TIB encontrados estão de acordo com os obtidos por Silva \& Kato (1998) confirmando que a cobertura vegetal afeta positivamente a capacidade de infiltração de água no solo.

Considerando-se os resultados obtidos e o trabalho de Sales et al. (1999) é razoável admitir-se que o teor de argila pouco contribui na magnitude dos valores da TIB, ou seja, a particularidade do Latossolo distroférrico em formar pequenos grânulos favorece a infiltração de água; entretanto, o tipo de manejo adotado que promove a compactação e, conseqüentemente, a redução da macroporosidade do solo, contribui sensivelmente para a redução da TIB, como pode ser verificado no valor da TIB obtido no tratamento 4 , relativo ao plantio convencional (Tabela 2). Este sistema de plantio vem sendo realizado há pelo menos cinco anos na área experimental, a exemplo de várias outras áreas de produção na região. $\mathrm{O}$ uso de grades agrava $\mathrm{o}$ aspecto relativo ao volume de macroporos, formando o denominado "pé de grade", que é uma camada adensada entre 10 e $30 \mathrm{~cm}$ de profundidade, conforme relatado por Alves Sobrinho et al. (2000).

\section{Equações para a estimativa da taxa de infiltração}

Os parâmetros $\alpha, \beta$ e k ajustados para os modelos, e os índices estatísticos, estão apresentados na Tabela 3. As curvas de taxa de infiltração estimadas pelos modelos e os dados observados nas determinações de campo, estão apresentados nas Figuras 1 a 4; pode-se afirmar, então que, de modo geral, a qualidade do ajuste dos modelos foi satisfatória. Tal afirmação se baseia na análise dos coeficientes de determinação $\left(\mathrm{R}^{2}\right)$ das regressões não-lineares ajustadas em cada tratamento estudado, com destaque para a equação de Horton, que apresentou valores de $\mathrm{R}^{2}$ sempre acima de 0,91 .

Tabela 3. Parâmetros e índices estatísticos estimados

\begin{tabular}{crrrr}
\hline \multirow{2}{*}{$\begin{array}{c}\text { Parâmetros } \\
\text { e Îndices }\end{array}$} & \multicolumn{1}{c}{ Trat1 } & \multicolumn{4}{c}{ Trat2 } & Trat3 & Trat4 \\
\cline { 2 - 5 } Modelo de Horton \\
\hline$\beta$ & $-0,1221$ & $-0,1487$ & $-0,1221$ & $-0,0667$ \\
CMR & 0,0043 & 0,0000 & 0,0130 & 0,0033 \\
CA & 1,0530 & 1,5468 & 0,9735 & 1,0811 \\
EF & 0,0031 & 0,0425 & 0,0015 & 0,0005 \\
\hline \multicolumn{5}{c}{ Modelo de Kostiakov-Lewis } \\
\hline$\alpha$ & 0,3471 & 0,3080 & 0,3641 & 0,5028 \\
$\kappa$ & 49,4347 & 16,2934 & 64,6132 & 89,7465 \\
CMR & $-0,0090$ & $-0,0024$ & $-0,0146$ & $-0,0333$ \\
CA & 1,2370 & 1,4082 & 1,2125 & 1,4786 \\
EF & 0,0030 & 0,0423 & 0,0015 & 0,0004 \\
\hline
\end{tabular}

Trat1 - Plantio direto (PD) sucessão soja-nabo; Trat2 - PD soja-aveia; Trat3 - PD soja-pousio; Trat4 plantio convencional

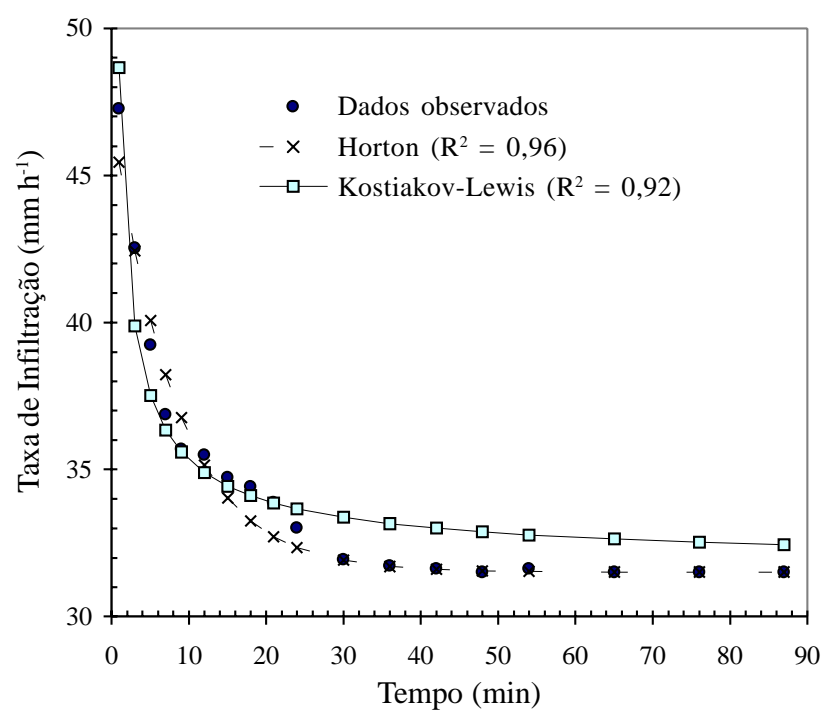

Figura 1. Taxas de infiltração em plantio direto: sucessão sojanabo 


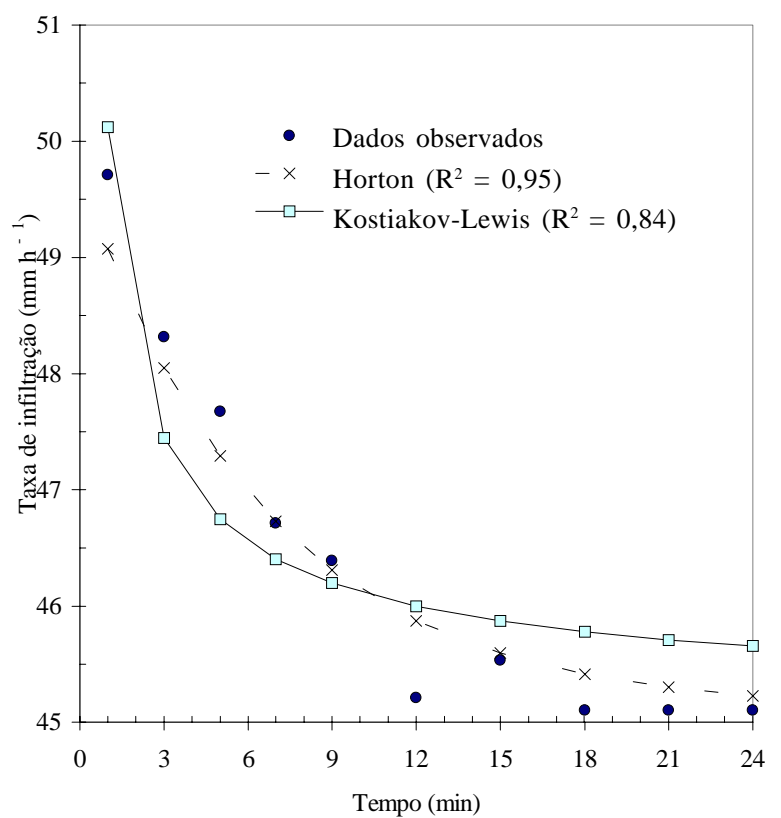

Figura 2. Taxas de infiltração em plantio direto: sucessão soja aveia

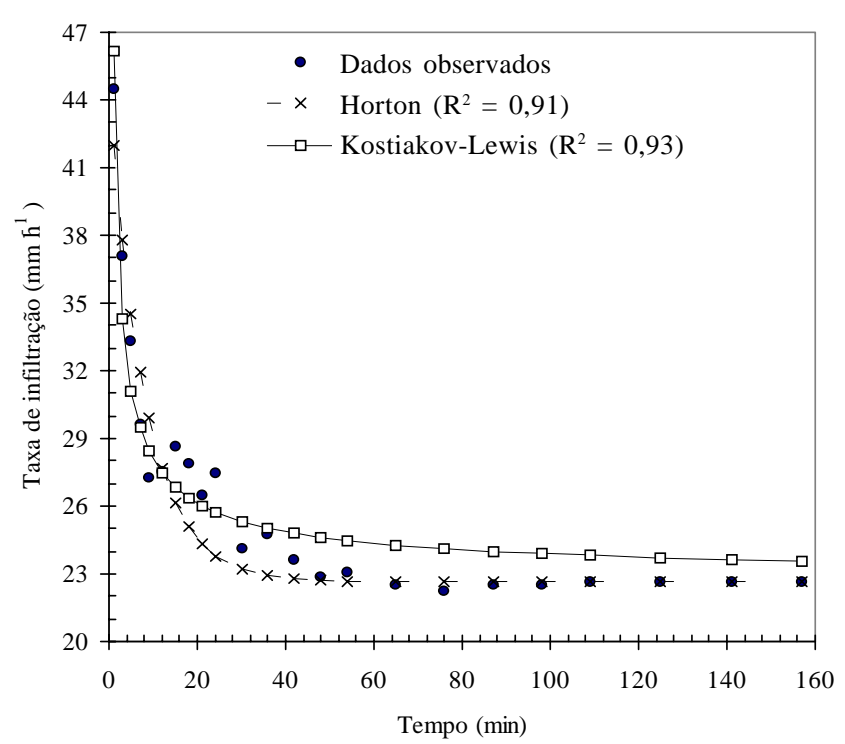

Figura 3. Taxas de infiltração em plantio direto: sucessão soja pousio

Analisando-se as curvas apresentadas nas Figuras 1 a 4, verifica-se que o modelo de Kostiakov-Lewis tende a superestimar os valores ajustados a partir do tempo de $10 \mathrm{~min}$, para os tratamentos sob plantio direto e, a partir de $20 \mathrm{~min}$, no tratamento relativo ao plantio convencional.

Analisando-se o coeficiente de massa residual, verifica-se que a equação de Horton subestima a taxa de infiltração, enquanto a de Kostiakov-Lewis a superestima, comportamento indicado pelos valores positivos do índice CMR das equações de Horton e negativos da de Kostiakov-Lewis (Tabela 3). Este índice estatístico também confirma o melhor ajuste da equação de Horton, com desvios mais próximos de zero. $\mathrm{O}$ coeficiente de ajuste e a eficiência foram também melhores na equação de Horton, para os quatro tratamentos. Os valores desses índices, mais próximos da unidade, ratificam esta equação como a mais

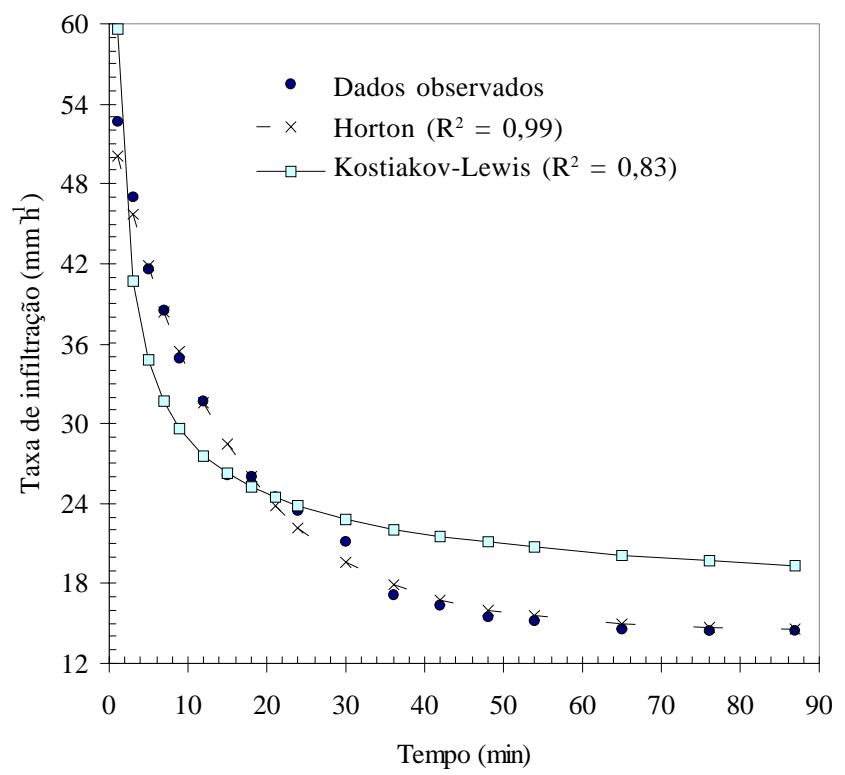

Figura 4. Taxas de infiltração em plantio convencional: sucessão soja - pousio

adequada para estimar a taxa de infiltração no tipo de solo estudado. $O$ único dado discordante foi o coeficiente de ajuste, concernente ao segundo tratamento explicado, conforme Libardi (1995) pelos curtos intervalos de tempo que ocorreram para a estabilização da infiltração.

\section{CONCLUSÕES}

1. O sistema de plantio direto apresentou valores de taxa de infiltração final de água no solo superiores ao preparo convencional e, entre os tratamentos estudados, a sucessão soja - aveia foi a que proporcionou maior valor de TIB

2. Os índices estatísticos usados permitiram evidenciar-se que a equação de Horton é a mais adequada para a estimativa da taxa de infiltração de água no solo estudado.

\section{LITERATURA CITADA}

Agassi, M.; Bradford, J.M. Methodologies for interrill soil erosion studies. Soil and Tillage Research, Philadelphia, v.49, p. 277-287, 1999.

Alves, M.C.; Cabena, M.S.V. Infiltração de água em um Podzólico Vermelho-Escuro sob dois métodos de preparo, usando-se chuva simulada com duas intensidades. Revista Brasileira de Ciência do Solo, Viçosa, v.23, p.753-761, 1999.

Alves Sobrinho, T.; Carvalho, D.F.; Aquino, R.M.; Montebeller, C.A. Programa computacional para a definição de parâmetros hidráulicos utilizados na determinação da energia cinética da chuva simulada em infiltrômetros de aspersão. Engenharia Rural, Piracicaba, v.12, n.1, p.28-35, 2001.

Alves Sobrinho, T.; Ferreira, P.A.; Pruski, F.F. Desenvolvimento de um infiltrômetro de aspersão portátil. Revista Brasileira de Engenharia Agrícola e Ambiental, Campinas Grande, v.6, n.2, p.337-344, 2002. 
Alves Sobrinho, T.; Peixoto, P.P.P.; Souza, L.C.F.; Fedatto, E.; Mapeli, N.C. Avaliação de alguns atributos do sistema soloágua-planta em plantio direto e convencional: Parte I. In: Congresso Brasileiro de Engenharia Agrícola, 30, 2000, Fortaleza. Resumos... Fortaleza, SBEA, 2000. CD-Rom

Bertol, I.; Beutler, J.F.; Leite, D.; Batistela, O. Propriedades físicas de um cambissolo húmico afetadas pelo tipo de manejo do solo. Scientia Agrícola, Piracicaba, v.58, n.3, p.555-560, 2001.

Carduro, F.A.; Dorfman, R. Manual de ensaios de laboratório e campo para irrigação e drenagem. Brasília: PRONI/MA, 1988. 216p.

EMBRAPA. Empresa Brasileira de Pesquisa Agropecuária. Sistema brasileiro de classificação de solos. Brasília: EMBRAPA - CNPS/EMBRAPA - SPI, 1999. 412p.

Ferreira, M.M; Fernandes, B.; Curi, N. Influência da mineralogia da fração argila nas propriedades físicas de Latossolos da Região Sudeste do Brasil. Revista Brasileira de Ciência do Solo, Viçosa, v.23, p.515-524, 1999.

Libardi, P.L. Dinâmica da água no solo, Piracicaba: Snt, 1995. 497p.

Meyer, L.D.; McCune, D.L. Rainfall simulator for runoff plots. Agricultural Engineering, St. Joseph, v.39, n.1, p.644-648, 1958.
Morin, J.; van Winkel, J. The effect of raindrop impact and sheet erosion on infiltration rate and crust formation. Soil Science Society of America Journal, v.60, p.1223-1227, 1996.

Prevedello, C.L. Física do solo com problemas resolvidos. Ed. SAEAFS. Curitiba, PR, 1996. 446p.

Reichardt, K. Dinâmica da matéria e da energia em ecossistemas. 2.ed. Piracicaba: Escola Superior de Agricultura Luiz de Queiroz, 1996.513p.

Reichert, J.M.; Veiga, M.; Cabeda, M.S.V. Selamento superficial e infiltração de água em solos do Rio Grande do Sul. Revista Brasileira de Ciência do Solo, Campinas, v.16, n.3, p.289-298, 1992.

Resende, M.; Curi, N.; Rezende, S.B.; Corrêa, G.F. Pedologia: base para distinção de ambientes. 4. ed. Viçosa: NEPUT, 2002.338p.

Sales, L.E.O.; Ferreira, M.M.; Silva, M.O; Curi, N. Estimativa da taxa de infiltração básica do solo. Pesquisa Agropecuária Brasileira, Brasília, v.34, n.11, p.2091-2095, 1999.

Silva, L.C.; Kato, E. Avaliação de modelos para a previsão da infiltração de água em solos sob cerrado. Pesquisa Agropecuária Brasileira, Brasília, v.33, n.7, p.1149-1158, 1998. 